\title{
Da estatística política à sociologia estatística. Desenvolvimento e transformações da análise estatística da sociedade (séculos XVII-XIX)
}

Olivier Martin ${ }^{1}$

Universidade de Paris V, Sorbonne CERLIS - Centre de Recherche sur les Liens Sociaux/CNRS

\section{RESUMO}

Este artigo analisa a história dos papéis e das funções das informações estatísticas nos Estados europeus (sobretudo na França) durante os séculos XVIII e XIX. As primeiras pesquisas estatísticas são irregulares e destinamse aos administradores fiscais, policiais ou militares dos Estados. Progressivamente, as pesquisas se tornaram mais regulares, mais autônomas perante as necessidades políticas diretas, e passaram a concernir aspectos cada vez mais diversos da vida social. Foi o caso, durante o século XIX na Europa: quase nenhum aspecto das sociedades escapou ao "olhar estatístico". Esse desenvolvimento foi acompanhado pelo nascimento das ciências humanas e sociais no final do século XIX: por exemplo, a sociologia francesa se apoiou muito cedo nos conhecimentos saídos das fontes estatísticas. A história institucional, metodológica e conceitual da sociologia francesa é muito diretamente ligada à história das instituições e pesquisas estatísticas.

Palavras-chave: Estatística; Sociologia; Política.

\section{ABSTRACT}

This article analyzes the history of functions and roles of statistical data in the European states (specially France) during the 17th, 18th and 19th centuries. The first statistical enquiries are irregular and are made for tax system, military or police forces. Enquiries progressively become more regular and more autonomous from the direct political needs, and they concerned more and more aspects of society: the "statistical eye" is wide open especially during the $19^{\text {th }}$ century in Europe. This development is going together with the birth of social science during the end of the $19^{\text {th }}$ century. French sociology is a good example of such story. The methodological, institutional and conceptual aspects of his history is closed to the history of statistical enquiries and statistical institutions.

Key Words: Statistical Data; Sociology; Politics. 
O século XIX viu florescer numerosas pesquisas estatísticas cobrindo domínios tão variados quanto a prostituição, as condições de vida dos operários, os traços antropométricos de conscritos ou de criminosos, os sistemas industrial e agrícola. Esses registros estatísticos tinham uma finalidade precisa: melhor delimitar o fenômeno para melhor controlá-lo ou nele intervir. Mas, progressivamente, esta finalidade "social e política" se desdobrou numa finalidade científica: melhorar o conhecimento de certos fenômenos sociais ou humanos. A crença na idéia de que um conhecimento quantificado dos fatos da sociedade permite melhor conhecê-los e eventualmente modificá-los era muito promissora, tanto para os administradores do Estado quanto para os cientistas. A estatística estava "quase por toda parte", era largamente difundida.

No entanto, cerca de dois séculos antes, aquilo que era conhecido como a estatística e as estatísticas apresentavam traços muito diferenciados: tratava-se antes de tudo de instrumentos contáveis, destinados a recensear as forças do país, a enumerar os homens e seus bens com fins puramente administrativos ou militares. Em certos casos, tratava-se mesmo de um instrumento da polícia. A estatística dependia então quase exclusivamente do Estado e de sua administração: nenhuma difusão pública era conceptível; o estabelecimento de conhecimentos científicos não era sua finalidade.

Centrado principalmente no caso francês, este artigo procura reconstruir as circunstâncias históricas do aparecimento de uma concepção moderna das estatísticas; ou antes, das circunstâncias da transformação dos dispositivos estatísticos exclusivamente destinados aos reis e a suas administrações, em dispositivos relativamente autônomos, quase universais e notadamente destinados a uma análise científica da sociedade. Esta transformação representa um dos traços da constituição das ciências humanas e sociais do século XIX.

RECENSEAMENTOS E PESQUISAS ANTES DE 1800: ADMINISTRAR E PROTEGER O TERRITÓRIO

Conflitos e problemas dos recenseamentos da população

As primeiras tentativas de enumeração de indivíduos ou de bens começam com os grandes impérios da Antigüidade, cujas estruturas administrativas eram fortes: preocupados em gerir e administrar seu império do melhor modo, os poderes centrais procuraram conhecer melhor sua extensão territorial e o número de seus súditos. Foi assim que as civiliza- 
ções egípcia, mesopotâmica e chinesa, como antes delas a civilização dos sumérios (5000 a 2000 a. C. ), realizavam pesquisas censitárias das quais alguns traços chegaram até nós. O objetivo desses recenseamentos era, antes de tudo, responder à necessidade da administração do império: responder às necessidades de mão-de-obra em vista da construção das grandes pirâmides; responder às preocupações fiscais; estabelecer as listas para a conscrição militar; melhorar a repartição dos habitantes sobre todo o território em vista de melhor utilização das terras.

Porém, os recenseamentos da população durante longo tempo encontraram obstáculos que tornavam sua realização inconcebível, seja materialmente, seja filosoficamente. Entre os obstáculos materiais existia certamente a necessidade de dispor de uma organização complexa e de uma estrutura administrativa ao mesmo tempo incontestada e ativa. Existia igualmente o temor, no seio da população, de ser recenseada com fins militares ou fiscais. Entre os obstáculos filosóficos, ou antes religiosos, havia, ao menos no mundo cristão ou hebraico, a atitude ambígua e mesmo contraditória afirmada na Bíblia: enumerar a população era uma atitude sacrílega por visar questionar o "segredo da Vida e da Criação", mas, ao mesmo tempo, Deus poderia ordenar os recenseamentos. Por exemplo, os diversos escritos sagrados relatam freqüentemente sob formas contraditórias os recenseamentos realizados na Antigüidade: um recenseamento pode ser descrito como ordenado por Deus, enquanto, segundo outra fonte, trata-se de algo vindo de Satã. ${ }^{2}$

Em certas circunstâncias estes obstáculos foram superados. Foi em particular o caso, e de modo durável, a partir de meados do século XVII em toda a Europa ocidental. Tal fase, que se abriu simultaneamente na França, na Alemanha e na Inglaterra, seguiu-se a um longo período de recuo de práticas censitárias centralizadas: o sistema feudal de parcelamento, os poderes, as condenações por Santo Agostinho ou Santo Ambrósio do pecado do orgulho cometidos quando dos recenseamentos da população humana perturbaram as tentativas de contagem da população; e isto, apesar de alguns progressos, notadamente em razão das necessidades fiscais e, a partir do século XIV, graças ao registro de atas de estado civil nas paróquias, inicialmente destinado a impedir os casamentos ilícitos entre parentes próximos.

Este renascimento está ligado a um período de crise política, econômica e religiosa, e de reorganização dos poderes na Europa ocidental; na França, sobretudo, a crise agrícola e econômica que o reino atravessou no final do século XVII (guerras, epidemias, fome, provável alteração do 
clima), a afirmação do controle da monarquia sobre as províncias do reino, e o desenvolvimento de uma administração centralizada e organizada (sobretudo por meio da ação do cardeal de Richelieu e do cardeal Mazarino, a "monarquia administrativa"), contribuiram para que os recenseamentos e pesquisas entrassem para o campo da ação administrativa. Circunstâncias comparáveis tiveram efeitos análogos em outros países europeus, Inglaterra e Alemanha especialmente.

\section{Pesquisas para a monarquia administrativa francesa}

$\mathrm{Na}$ França, o recenseamento da população e dos bens foi incontestavelmente percebido como instrumento de governo: deveria permitir o estabelecimento de necessidades alimentares dos súditos do rei, manter os registros de polícia e o registro dos sujeitos a taxas e impostos (gabela, talha), construir estatísticas de "fogos" para estabelecer a repartição geográfica dessas taxas e impostos, constituir listas de homens aptos para a guerra ou fazer o inventário da subsistência (notadamente após as crises alimentares ou guerras). Tratava-se, de certa maneira, de uma contabilidade. Por exemplo, em 1634, Richelieu deseja ver realizado um recenseamento geral dos franceses, e em 1637, ele realizou um censo dos parisienses a fim de calcular suas necessidades alimentares. Nos anos 1660, Colbert ordenou "confrontar o papel do imposto com o da talha e mesmo fazer uma informação sumária [...] do número de habitantes que estão em cada paróquia ou comunidade, a fim de poder fazer uma nova cobrança de impostos, mais justa e proporcional ao número dos ditos habitantes" ${ }^{3}$.

Seguiram-se muitas outras pesquisas, sempre provocadas por Colbert. Após 1680, sucedendo Colbert, Vauban, autor do famoso Projet de dîme royale, e também de um fascículo Méthode générale et facile pour faire le dénombrement des peuples (1686), tendo alcançado um certo sucesso junto aos administradores do reino, iniciou pesquisas censitárias. Ele propõs juntar às operações simples de contagem de pessoas o registro de seu sexo, idade e profissão (eclesiásticos, nobreza, religiosos, domésticos, servos), bem como o censo dos meios de produção (terras cultiváveis, campos, bosques, vinhedos, rebanhos, moinhos...). ${ }^{4}$ Para ele,

(...) esses recenseamentos têm sua utilidade porque sempre mostram o estado em que se encontra o crescimento e enfraquecimento dos povos, fundos de terra e animais, que é a meu ver uma coisa a que se deve dar uma grande atenção e que deveria ser uma das principais regras do bom governo dos Estados [...]. Essas revistas (ou censos) merecem ser cuidadosamente 
registradas em todas as sedes dos principais lugares de administração das cidades, para que de tempos em tempos possam ser comparadas umas com as outras e recorrer-se a elas.

De resto, seu famoso projeto de reforma do dízimo real (substituição do sistema de taxas e impostos por um imposto único em que nenhum privilegiado seja isento), cuja divulgação foi interditada pela polícia de Luís XIV, apóia-se sobre os conhecimentos que as pesquisas deveriam fornecer.

As investigações constituiam técnicas de Estado, instrumentos de gestão e administração: elas não estavam ligadas a preocupações de ordem imediatamente científica (economia, demografia). Tal pragmatismo foi bem expresso por Jean Bodin, que via uma "utilidade infinita" nos recenseamentos:

primeiramente, quanto às pessoas, sabe-se o número, a idade e a qualidade; quanto se poderia dali tirar, seja para a guerra, para permanecer no local ou para enviar às colônias, seja para empregar nos trabalhos e corvéias de reparação e fortificações públicas, seja para saber as provisões e os víveres que seriam necessários aos habitantes de cada cidade. ${ }^{5}$

É nesta perspectiva pragmática que pode ser situada a grande pesquisa dos intendentes durante o final do reinado de Luís XIV (1697-1700), a qual deveria permitir determinar-se a "carga que cada um pode carregar". Foi igualmente a pesquisa de respostas imediatas a questões de ordem administrativa que motivou, logo depois dos primeiros eventos revolucionários, em dezembro de 1789 , a programação de um levantamento encarregado de reunir a informação necessária para proceder ao recorte do território nacional em vista da criação dos departamentos, para assegurar a boa fundamentação e o equilíbrio desse recorte, e depois, no interior desses departamentos, para estabelecer a hierarquia administrativa entre as cidades segundo sua importância.

Essa necessidade de conhecimento com fins contábeis e administrativos se desdobrou, com freqüência, numa necessidade de controle, de vigilância: as pesquisas estatísticas constituíam, de uma certa maneira, investigações de polícia. A grande pesquisa organizada por pedido do controlador geral de finanças Orry em 1745 é, deste ponto de vista, reveladora: não somente foram solicitados generalidades aos intendentes: o número de "rapazes em idade de quinze a quarenta e cinco anos, sujeitos à milícia e capazes de portar armas" (a fim de poder fazer a guerra de sucessão da Áustria), os recursos que poderiam ser encontrados "em cada 
cidade de província e nas paróquias do campo para o aumento das rendas do Rei", bem como a descrição da "prataria constituida por baixela de prata e outras obras de ourivesaria”; mas lhes era pedido também semear "os rumores de um aumento de um terço sobre todos os direitos das entradas" e de " recrutamento de uma futura milícia de dois homens em cada paróquia”, e de "recolher com cuidado o que dirão disso os habitantes". Foi também o que exprimiu, sob uma forma diferente, Jean Bodin no final do século XVI: "será visto também pela contagem, de que ofício cada um se ocupa, de que ganha sua vida, a fim de caçar republicanos ... as moscas, as vespas que comem o mel das abelhas, e banir os vagabundos, os desocupados, os ladrões “.

Ao lado de suas motivações ligadas às necessidades de administração e de controle do território e dos súditos do reino, e ao menos durante os regimes monárquicos, os empreendimentos de contagem tiveram um outro objeto: a educação do príncipe ${ }^{6}$. Tratava-se de instruir o príncipe do estado de seu reino pela descrição, sintética, dos homens, bens, instituições, território. $\mathrm{O}$ olhar era descritivo mas também apologético: o retrato do reino era também o retrato do soberano, de sua potência, de sua grandeza. Por exemplo, foi nesta perspectiva que se inscreveu Fénelon, preceptor do duque de Borgonha, herdeiro do trono, que procurou promover pesquisas visando conhecer o estado do reino por meio do recenseamento da qualidade das terras, da produção de trigo e de vinho, do número de homens, dos costumes, das profissões, das ocupações, " tudo tão detalhado o mais possível": "Sabeis o número de homens que compõem vossa nação; quantos homens, quantas mulheres, quantos trabalhadores, quantos artesãos, quantos práticos, quantos comerciantes, quantos padres e religiosos, quantos nobres e militares? Que se poderia dizer de um pastor que não soubesse o número de seu rebanho?" Em suma, o "rei ignorante de todas essas coisas não é rei senão pela metade”.

Dessa forma, esta tradição de "espelhos do príncipe”, saída do mundo medieval, visou fornecer ao príncipe uma imagem de sua potência, mas também instruí-lo sobre seus deveres para com seu reino, para com seu povo. A religião, a moral ou a arte da guerra não bastavam para governar: o monarca deveria possuir instrumentos práticos, uma ciência para a ação e o governo de seu reino. Nisto se reúnem os dois olhares das informações estatísticas, educação do príncipe e administração do reino. 
Ao lado dessas vontades francesas de ver realizar contagens e descrições dos constituintes do país com fins administrativos (no sentido largo), existiram outras formas "de empreendimentos estatísticos" que contribuíram para a constituição do que concebemos hoje como a estatística: a Statistik alemã e a aritmética política inglesa também participaram, com razões diversas, na constituição de saberes e dispositivos, permitindo alcançar e descrever os constituintes de uma sociedade, de uma nação e da diversidade de seus constituintes. Essas duas abordagens apresentam no entanto traços muito diferentes.

A aritmética política inglesa, saída dos trabalhos de John Graunt, William Petty, Charles Davenant e Gregory King a partir da segunda metade do século XVII, tem olhares teóricos precisos: conseguir calcular os fenômenos relativos à cidade a fim de fornecer instrumentos matemáticos quantitativos aos governantes. Foi o que exprimiu Petty: "o método que emprego não é ainda muito comum pois, em lugar de me servir somente de termos no comparativo e superlativo e de argumentos puramente racionais, adotei o método que consiste em exprimir-se em termos de números, pesos e medidas". O cálculo, repousando sobre uma coleta de informações reduzida ao mínimo, deveria permitir a substituição de levantamentos exaustivos e recenseamentos que, na concepção liberal da ordem política e social que prevalecia na Inglaterra, eram dificilmente conceptíveis.

Parecia, de fato, inconcebível exercer uma curiosidade muito grande sobre uma população apegada à sua liberdade e a seus direitos individuais. Em 1753, por exemplo, um projeto de recenseamento, criticado como responsável pela ruína completa das últimas liberdades dos ingleses, foi rejeitado pelo Parlamento. Entre essas liberdades ultrajadas, está a das "classes possuidoras" que viam nos recenseamentos um procedimento para conduzi-las a expor seus bens aos olhos de todos? ${ }^{7}$. No início do século XIX, muitos ainda lamentavam a existência de registros paroquiais e boletins de mortalidade, cuja existência era no entanto obrigatória desde 1758. De fato, o estado civil só foi generalizado e laicizado em 1836.

Os aritméticos políticos interessavam-se tanto pelos problemas econômicos quanto pelos demográficos. Mais concretamente, tratava-se por exemplo de estabelecer tabelas de mortalidade pelo cálculo de seguros ou de rendas vitalícias (ligadas ao desenvolvimento dos empréstimos de Estado e de tontines ), de estimar a população geral da Inglaterra ou do País de Gales pelo cálculo (e não pelo recenseamento). $\mathrm{O}$ aparecimento de téc- 
nicas matemáticas para o estudo da proporção de mortes e nascimentos numa população fazia parte de uma revolução cultural da relação entre eventos até então percebidos como mágicos (astrologia) ou teológicos. Imaginar que a morte pudesse seguir leis matemáticas, estatísticas ou probabilísticas solicitava importantes mudanças nas representações das causas da vida e da morte pelos indivíduos.

Esta mudança cultural, bem como os avanços técnicos nos instrumentos de cálculo tornaram possível, durante o século XVIII e sobretudo no XIX, o importante desenvolvimento do cálculo econômico, político e social. O triunfo do "espírito de cálculo" durante o século das Luzes teve como resultado reforçar o interesse que os sábios e eruditos traziam à abordagem científica quantitativa inglesa, e o progresso das ciências matemáticas (cálculo das probabilidades ${ }^{8}$ ) permitiu aos aritméticos políticos alcançar respostas a seus questionamentos. A Matemática social de Condorcet', as Quaestiones calculi politici de Leibniz, o Essai de politique et de morale calculée, do francês d'Harcanville, o Essai d'arithmétique morale de Buffon, a obra Die Göttliche Ordnung (L'Ordre Divin, 1741) do pastor alemão Süszmilch ${ }^{10}$, ou ainda os Essais d'arithmétique politique de Lagrange constituem exemplos do interesse de muitos cientistas europeus pela abordagem quantitativa aparentada com a aritmética inglesa: todos têm por objeto resolver pelo cálculo as dificuldades da gestão dos Estados. Mais ainda, a Enciclopédia de Diderot e d'Alembert define a "Aritmética política" como aquela que tem por finalidade "pesquisas úteis à arte de governar os povos" (1751).

Por sua vez, a Statistik ${ }^{11}$ alemã tinha por ambição principal o conhecimento sintético de toda sociedade humana (burgo, cidade, região ou Estado): ela visava alcançar a "potência singular" desta sociedade pela descrição de todos os seus traços (clima, geografia, poderes e atividades econômicas, recursos naturais, demografia, poderes políticos, etc.), pelo conhecimento de sua "morfologia”. Os produtos desta abordagem, fortemente empíricos e pouco explicativos, não eram necessariamente (e mesmo raramente) quantitativos: no essencial, eram de natureza literária.

A Statistik alemã se originou nas múltiplas descrições "de estados, impérios ou principados do mundo", produzidos localmente por eruditos e administradores e que, desde a segunda metade do século XVI, graças ao desenvolvimento da imprensa de massa, se difundiram (notadamente graças à editora holandesa Elsevier ). Mais tarde (segunda metade do século XVIII), essas fontes de informação foram substituídas por aquelas produ- 
zidas, oficialmente, pela administração territorial que viu então aumentar seu empreendimento e, portanto, seu poder de coleta de informações.

A massa crescente de informação empírica acumulada tornou cada vez mais necessários os princípios de organização e síntese, assim como os princípios de crítica das fontes. Estudiosos e universitários (H. Conring, J. Zedler, G. Achenwall...) empreenderam a organização de todos esses fatos acumulados e a proposição de sínteses, as monografias: por exemplo, em 1754, A. F. Büsching empreendeu a publicação de sua Descrição do mundo inteiro e, alguns anos mais tarde, criou uma revista em parte destinada à difusão de informações estatísticas; e, na mesma época, o universitário Gottfried Achenwall difundiu o termo estatística no qual via a ciência da constituição do Estado, isto é, a ciência dos recenseamentos de todos os constituintes de um Estado. Assim se desenvolveram os saberes e métodos constituintes de uma estatística descritiva (ou morfológica), isto é, dos princípios da organização dos conhecimentos, das nomenclaturas, dos instrumentos de comparação de dados (quadros cruzados de critérios de avaliação e de entidades a serem comparadas, Estados ou regiões, por exemplo).

Progressivamente, durante os séculos XVII e XIX, a abordagem francesa (centrada nos recenseamentos e nas descrições do país com fins administrativos e contábeis), a abordagem alemã (centrada numa abordagem descritiva e analítica, raramente quantificada) e a abordagem inglesa (centrada na aritmética e na análise matemática de dados quantitativos) vão se encontrar e dar nascimento à estatística tal como nós a conhecemos hoje, isto é, ao mesmo tempo "ciência da contagem dos constituintes da sociedade" e "ciência do cálculo em vista da análise das contagens". Este encontro duradouro, que havia antes acontecido de forma pontual e circunscrita no espaço, foi possível graças às traduções, adaptações, "mediações". Entre as "mediações" que permitiram a difusão dos instrumentos saídos da aritmética inglesa, é preciso contar as trocas regulares entre os eruditos franceses, alemães e ingleses sobre os instrumentos do cálculo estatístico e probabilístico. De uma certa maneira, no final do século XVIII a França se adiantava em relação à Inglaterra no uso dos instrumentos probabilistas nos cálculos de contagem, nos métodos de estimativas de população. Além disso, os trabalhos estrangeiros (alemães, ingleses, mas também dinamarqueses...) foram traduzidos e difundidos na França, notadamente por meio do Bureau de Estatística do Ministério do Interior após 1800 .

É claro que a existência e o encontro dessas diferentes tradições, umas 
mais literárias e descritivas, outras mais matemáticas e sintéticas, não aconteceram sem debates nem controvérsias. Entre as controvérsias, podemos assinalar aquela relativa aos quadros sintéticos e que ocorrereu no início do século XIX na França, no Bureau de Statistique. A introdução de quadros sintéticos, cruzando as entidades a comparar (países, províncias, generalidades, comunas...) com critérios de comparação (superfície, características econômicas, população...), despertou a crítica dos defensores da concepção mais descritiva e literária da estatística: Como seria possível comparar entidades que possuem identidade própria e irredutível? A comparação não seria puramente artificial, pois esquece as singularidades? Os termos desta controvérsia estão presentes nos debates ocorridos, entre 1800 e 1806, entre dois membros ativos do Bureau de Statistique: Peuchet et Duvillard.

A eles se juntaram debates sobre a possibilidade de condução dos cálculos a partir de estatísticas, de estabelecer leis matemáticas sobre os fatos humanos: Duvillard avaliava que com os dados necessários, "aquilo que não pode ser contado ou medido imediatamente, pode ser descoberto pelo raciocínio e pelo cálculo, pela combinação metódica dos fatos”; enquanto Peuchet considerava indispensável rejeitar o método que "por fórmulas enigmáticas, cálculos algébricos ou figuras de geometria, queira apresentar ou analisar aquilo que pode ser dito de modo bem mais simples e sem obscuridade".

\section{A FEBRE ESTATÍsTICA DO SÉCUlO XIX}

\section{A produção das estatísticas: da urgência à rotina}

No decorrer do século XVIII, simultaneamente ao encontro dessas tradições, as práticas de registro estatístico pouco a pouco se dissociaram das necessidades administrativas e gestionárias imediatas, das preocupações contábeis e financeiras dos administradores reais ocupados em gerir o quotidiano e por vezes a urgência (crises, guerras, fomes). Uma estatística mais regular, mais centralizada, relativamente independente das demandas pontuais e urgentes da administração, parcialmente liberada das demandas política, econômica, climática ou social, surgiu progressivamente. Na França, devido aos eventos políticos e à necessidade de fazer pesquisas para responder às necessidades de reformas revolucionárias, este surgimento foi caótico; não foi por isso menos real. Real com efeito, por exemplo, a vontade do ministro do interior François de Neufchâteau 
(1797-1800) de ver sistematizar e repetir regularmente os registros estatísticos, mesmo que não tenha tido tempo de concluir seus projetos.

De outro lado, foi durante a segunda metade do século XVIII e nas primeiras décadas do XIX que emergiu os organismos oficiais encarregados de realizar as pesquisas estatísticas, de reunir as informações estatísticas e de assegurar sua difusão junto aos governantes e ao público. Em 1756, a Alemanha e a Inglaterra criaram o primeiro organismo oficial de estatística. Na França, em 1784, Necker propôs a criação de um Bureau central de pesquisa e ensino, "encarregado de recolher todas as informações de ordem econômica, social e demográfica”. Um pouco antes de 1800, François de Neufchâteau lançou as premissas de um serviço desenvolvido de estatística (sobretudo com a criação de uma cadeira de estatística no Collège de France). Seu projeto se concretizou sem ele em 1800: o novo ministro do interior, Lucien Bonaparte, criou o Bureau de Statistique, ligado ao seu ministério.

As administrações da Primeira República e depois do Império fizeram prova de uma verdadeira vontade de se prover de um aparelho estatístico capaz de assegurar periodicamente as coletas de informações, tanto de natureza econômica quanto demográfica e social. Chaptal, que sucedeu Lucien Bonaparte no Ministério do Interior em 1801, e portanto à tutela do Bureau de Statistique, deu à estatística uma função ambiciosa, ainda mais afastada das preocupações imediatas da administração. Ele solicitou aos prefeitos que lhe enviassem, trimestre por trimestre, um quadro recapitulado da situação de seus departamentos (meteorologia, população, mendicância, crimes, processos, preços, grãos, contribuições), além de todas as informações relativas "às alegrias e tristezas dos habitantes do departamento e a seus costumes”. Esses dados permanentes e regulares constituem as famosas "estatísticas dos prefeitos", considerados hoje pelos estatísticos como o primeiro recenseamento geral verdadeiro da população.

Na França, a centralização da organização da administração monárquica, napoleônica ou republicana, facilitou a tarefa de todos os sucessores do Bureau de Statistique: o Bureau de Statistique Générale (1833$1840)^{12}$, depois Statistique Générale de la France (1840-1841). A marcha das estruturas destinadas à produção estatística e à centralização das informações estatísticas foi lenta mas irreversível. A autonomização crescente dos organismos encarregados da produção e da análise das estatísticas progressivamente permitiu a estas alcançar uma difusão pública. Pouco a pouco se levantou o véu de informações cujo segredo era até lá perfei- 
tamente guardado, sobretudo porque as estatísticas eram consideradas simples instrumentos de gestão, simples meios de administração e, portanto, parte dos arquivos pessoais dos administradores do reino.

Pouco a pouco o público foi associado e informado: desde então as estatísticas não constituem mais um "espelho" para o príncipe e seus administradores, mas um espelho da nação para a nação, ou um espelho da sociedade para a sociedade. Os recenseamentos foram regidos por leis após a Revolução Francesa. E foi o povo francês, por meio de seus representantes no parlamento, quem votou essas leis. Em 1791, por exemplo, uma lei colocou o princípio de um recenseamento geral. Um outro se seguiu em 1793-1794. Em seguida, fora dos períodos de crises graves, sua organização será regular: 1801, 1806, 1821, 1826, 1831, 1836, 1841, 1846, etc.

Ao mesmo tempo em que as práticas estatísticas se intensificaram nos ministérios ou organismos paraadministrativos, apareceram diversas instituições "independentes" nos níveis nacional e internacional. Elas reuniram os administradores das estatísticas oficiais, os estatísticos independentes e os pesquisadores sociais “amadores”. Foi sobretudo o caso da Société Statistique de Paris (SPP), criada em 1860, que tinha por objeto "popularizar as pesquisas estatísticas por meio de seus trabalhos e publicações” (artigo primeiro dos estatutos). Villermé, Michel Chevalier e Hyppolite Passy estavam entre seus fundadores.

A informação do público, em todo caso, a difusão em outros círculos além da administração passou por publicações: as revistas de publicação regular, a Feuille du cultivateur a partir de 1790, a Bibliothèque Commerciale e Annales de statistique a partir de 1801, os Archives générales de médecine desde 1823, como diversas obras de síntese (Annuaire politique et économique em 1799, Statistique élémentaire de la France em 1805, Description topographique et statistique de la France em 1810). Por exemplo, as pesquisas feitas trimestralmente junto aos prefeitos a partir de 1801 foram objeto de uma publicação no jornal dos Annales de statistique, e a criação da estatística geral da França em 1833 foi acompanhada da publicação de volumes regulares ${ }^{13}$; assim também a criação do Ministério da Instrução Pública em 1829 foi acompanhada pela realização e publicação de pesquisas regulares sobre as diferentes ordens de ensino; assim como, ainda, as estatísticas sobre as entradas, saídas e óbitos nos estabelecimentos hospitalares públicos são publicadas desde 1833.

Ao lado dessas publicações especializadas, outras revistas cuja finalidade principal não era a informação estatística abriram suas páginas a esta: é o caso do Journal des Arts et des Sciences, do Magasin encyclopédique ou 
de Décade. Um exemplo célebre é o de Sébastien Bottin que lançou uma empresa de almanaques departamentais por volta de 1800: o sucesso de sua empresa fez de seu patronímico um nome comum. A SPP publicou igualmente um jornal que ofereceu uma tribuna aos pesquisadores e administradores tão diversos quanto Émile Cheysson, aluno de Le Play, e muitos membros da família Bertillon, responsável pelo Bureau des Statistiques da cidade de Paris. Eles publicaram sobretudo dados relativos às causas dos óbitos e às condições sanitárias.

O século XIX foi incontestavelmente o século da difusão da técnica estatística e das estatísticas. Ele foi também o século da instauração da realização regular de congressos internacionais de estatística (ambos a cada quatro anos a partir de 1853) destinados a organizar metodicamente a coleta das observações científicas: as administrações nacionais especializadas estavam ali presentes e, pouco a pouco, se constituiu uma rede internacional de estatísticos e de estatísticas. Esses congressos, ainda que perturbados pela guerra franco-prussiana, chegaram em 1885 à criação do ISS (Institut International de Statistique). Internacionais, esses congressos e o instituto foram em grande parte autônomos em relação aos poderes políticos dos países representados: as preocupações dos membros eram desmarcadas daquelas das autoridades governamentais ${ }^{14}$.

No prolongamento da evolução que no final do século XVII e início do XIX havia alcançado os organismos nacionais em seus laços com sua administração de tutela, os organismos estatísticos internacionais desfizeram um pouco mais as ligações que uniam historicamente os poderes políticos aos dispositivos estatísticos: ao menos em parte, a produção das estatísticas se tornou um fim em si, destacado das preocupações gestionárias e administrativas imediatas, em todo caso não imediata nem necessariamente ditadas pelo poder político central. Ao se reunirem em escala internacional, os estatísticos deram nascimento a diversas nomenclaturas destinadas a facilitar as comparações internacionais de dados: as classificações internacionais das doenças, as causas dos óbitos são por exemplo saídas dos congressos do ISS.

\section{A multiplicação dos campos da estatística}

Juntamente com esta progressiva autonomização e desenvolvimento da difusão pública, a vontade de registrar e contar tudo se afirmou: "uma verdadeira febre estatística" parecia alcançar os administradores do reino durante a segunda metade do século XVIII e durante o XIX, notadamen- 
te a partir do período revolucionário e da Primeira República. Na França, em 1772, o abade Terray, controlador geral das finanças, instaurou um levantamento anual de nascimentos, óbitos e casamentos. Este levantamento foi efetuado até 1790 . Nessa mesma época, os intendentes adquiriram o hábito de registrar os preços dos produtos agrícolas e industriais e de transmitir, cada semana, uma síntese deles a Paris. E, último exemplo, na véspera da Revolução (1775-1786) o barão de Montyon recenseou e analisou sistematicamente cerca de dez mil pessoas julgadas e condenadas em matéria criminal pelo parlamento de Paris ${ }^{15}$.

Durante o período revolucionário, sobretudo por causa de numerosas necessidades dos múltiplos governos e assembléias, as pesquisas proliferou: pesquisas sobre os animais e forragens, sobre adubos, arados, lençóis, papelaria, minas e metalurgia, contagem dos grãos, da população, dos cidadãos em estado de portar armas ... Sob a Primeira República, vastas "pesquisas gerais" se realizou ou foram programadas: destinadas a construir um quadro da França e a mostrar "a vantagem de um governo livre e o bem que ele irá fazer”, essas pesquisas abordam até 175 temas referentes à agricultura, riquezas minerais, pesca, manufaturas, população, ciência e técnicas. O olhar era político mas também, e talvez tanto quanto, enciclopédico: as pesquisas deveriam servir às ciências, às artes e à administração. Durante o Império, o Bureau de Statistique e os diferentes ministérios ligados à indústria e ao comércio empreenderam também diversas pesquisas: sobre as minas, as forjas, os têxteis, a produção agrícola (oliveira, laranjeira, limoeiro, milho, tabaco, forragem, rebanho, mel, cera, linho ...). A partir de 1811, levantamentos mensais de grãos, frutos, forragens, algodão, índigo, beterraba e tabaco foram realizados em cada departamento. Uma vasta pesquisa sobre os três reinos, mineral, vegetal e animal, foi organizada em 1812.

A "febre estatística" atingiu igualmente as pesquisas eruditas privadas: médicos, viajantes, geógrafos, elites locais da França multiplicaram os empreendimentos de observação, descrição e análise da sociedade e de seus constituintes ${ }^{16}$ : relatos de viagens, descrições geográficas, coletas de informação organizadas pelos eruditos acadêmicos das províncias, inventário de patrimônio, plano médico da França, quadro dos temperamentos dos franceses... Essas iniciativas repousam em parte sobre tradições relativamente antigas: desde o século XVII, os beneditinos estabeleciam quadros e inventários de territórios e procuravam recolher saberes enciclopédicos sobre as regiões e reinos.

Mas somente durante os séculos XVII e XIX as práticas privadas (ou 
semiprivadas) de descrição e análise tomaram verdadeiramente impulso, se difundiram e apresentaram aspectos estatísticos. A filosofia das Luzes, e sua inoculação no conjunto da sociedade, evidentemente contribuiu para isso. É preciso também considerar, no Antigo Regime, o segredo que cercava todas as informações de ordem estatística e que portanto, involuntariamente, contribuiu para esse desenvolvimento de inquéritos e pesquisas privadas (apoiando-se, sobretudo, na abordagem aritmética inglesa que, de um lado, visa fazer observações exaustivas). Após o período revolucionário, elas foram encorajadas pelos poderes públicos que viam ali uma fonte de enriquecimento de suas próprias informações estatísticas. É isto que Chaptal, por exemplo, exprime em 1801: "Eu certamente não tive a intenção nem de proibir os trabalhos desse tipo aos sábios que quisessem a eles se dedicar, nem de tirar deles os auxílios que eles podem esperar da administração, nem de me privar das luzes que posso retirar de suas pesquisas."

As estatísticas morais

A "febre estatística” crescente durante os séculos XVIII e XIX se tornou cada vez mais abrangente das dimensões sociais do Reino, do Império ou da República. Por exemplo, as edições sucessivas da Nouvelle description de la France do geógrafo Piganiol de la Force consagram um lugar crescente à história e à descrição social: a terceira edição (1754) abrange, por exemplo, longos desenvolvimentos, ausentes até então, sobre os usos e gêneros de vida do povo. É nesta perspectiva de febre das descrições estatísticas sociais que se situam incontestavelmente as pesquisas lançadas pelos médicos (através da Société Royale de Médecine) em 1776-1778: pretendiam estabelecer um "plano topográfico e médico da França no qual o temperamento, a constituição e as doenças dos habitantes de cada província ou cantão seriam considerados relativamente à natureza e à exploração do solo".

Durante o século XIX, teve início uma verdadeira era de entusiasmo pela estatística social ou antes “moral”. É possível, como sugere Michelle Perrot, considerar que "o estatístico, novo geômetra, se tornou com o médico, outra face da ciência ordenadora, o grande especialista social, capaz de tomar a medida de tudo" ${ }^{17}$. Por exemplo, desde 1803, em seguida às tentativas do magistrado Montyon no final do Antigo Regime, que havia classificado e contabilizado os condenados por crime (segundo seu sexo, idade, qualidades, profissões, lugar do delito, e tipo de condenação), 
as estatísticas sobre as condenações por crime eram feitas e publicadas. A partir de 1827, os volumes do Compte Général de l'Administration de la Justice Criminelle foram publicados anualmente pelo Bureau de Statistique Judiciaire. Foi também o caso a partir de 1831 para as contas da justiça comercial e civil. Esses volumes compreendem ao mesmo tempo um comentário geral sobre a situação anual e sua evolução e quadros estatísticos relativos aos diversos crimes e delitos. Esses quadros apresentam uma grande riqueza de informação: eles trazem em particular informações sobre sexo, idade, estado civil, domicílio, lugar de residência, grau de instrução, profissão e estatuto (assalariado, desocupado, independente) dos acusados.

Sob o Império, foram empreendidas pesquisas estatísticas sobre as classes notáveis e burguesas: foram estudadas a estrutura da família, a escolaridade dos filhos, a beleza das filhas, o montante do dote ... Um outro exemplo, famoso, de estatísticas morais é fornecido pelo trabalho de Alexandre Parent-Duchâtelet, membro do conselho de salubridade da cidade de Paris, sobre a prostituição parisiense. A pesquisa, feita entre 1827 e 1835, publicada postumamente em 1836 sob o título De la prostitution dans la ville de Paris, considerée sous le rapport de l'hygiène publique, de la morale et de l'administration ${ }^{18}$, apresenta uma dimensão etnográfica e uma forte dimensão estatística: estatísticas comparativas da população das prostitutas em Paris e em outros departamentos franceses; estatísticas sobre as profissões exercidas pelos pais e testemunhas do ato do nascimento das filhas, seu grau de instrução, as causas de seu estado de prostituídas, a cor dos cabelos e dos olhos, sua constituição física...

Parent-Duchâtelet foi um dos higienistas presentes na criação dos Annales d'hygiène publique et de médecine légale publicados a partir de 1829 e ligados ao nascimento dos Conselhos de Salubridade Pública em várias grandes cidades (entre 1822 e 1830). Esses Annales, que tomam um grande espaço na pesquisas e estatísticas sociais, constituem a principal tribuna do movimento higienista; movimento que estimou possível diminuir a morbidade pela melhoria das condições de circulação dos dois elementos fundamentais que unem os seres entre si: a água e o ar. Suas pesquisas, que levaram às medidas de saneamento da água e escoamento das águas usadas, haviam notadamente recorrido a dados estatísticos para mensurar a relação entre a morbidade e as características do meio ${ }^{19}$.

Entre essas características, os higienistas não privilegiaram as condições naturais mas as condições econômicas e sociais: condições de vida, insuficiência psicológica do nível de vida do meio operário, o impacto 
da industrialização e da promiscuidade. Entre os higienistas, um dos mais famosos, Louis-René Villermé, conduziu as análises da influência do nível de renda sobre a morbidade (em torno de 1828-1830). Outros autores fizeram pesquisas mais centradas sobre a delinqüência, o alcoolismo ou a miséria. Seus trabalhos constituem ilustrações notáveis das novas tarefas atribuídas aos estatísticos: fazer obra social, identificar, para melhor administrar, os males da sociedade.

A preocupação com o social, entendida aqui no sentido amplo, isto é, no sentido médico, policial, socioeconômico e das condições de vida dos menos favorecidos, e por vezes dos temores que são ligados a eles, se encontra também em outras pesquisas estatísticas feitas durante o século XIX. Citemos rapidamente as pesquisas do ministro da instrução pública Guizot, sobre o estado moral da instrução primária (1830), as de Frédéric Le Play sobre o orçamento das famílias operárias (a partir de 1829), outras sobre o consumo nas grandes cidades (1847), sobre os surdos-mudos (1823) e cegos (1831), os alienados e seus asilos (1841-1860)... é também possível pensar na coleta dos dados antropométricos pelos sábios da Société Anthropologique de Paris, e notadamente Paul Broca durante a segunda metade do século XIX.

Todos esses trabalhos encontraram na estatística e na quantificação um instrumento que permitia alcançar conhecimentos objetivos sobre o homem e sua sociedade, e mais, administrar um território ou um povo.

\section{A BASE ESTATÍSTICA DA SOCIOLOGIA}

Esse desenvolvimento das informações estatísticas e de sua relativa difusão fizeram nascer as ambições teóricas, simultaneamente políticas e científicas. A ciência estatística, ao mesmo tempo em suas dimensões matemáticas (as técnicas estatísticas e probabilísticas, pouco evocadas aqui) e em suas dimensões ligadas à produção de dados, é incontestavelmente associada ao desenvolvimento das ciências humanas e sociais durante os séculos XIX e XX.

É claro que o desenvolvimento da estatística não constituiu o traço único que caracteriza o século XIX. Porém, associado ao desenvolvimento das ciências humanas e a outras evoluções intelectuais (por exemplo, a idéia de que o biológico desempenha um papel determinante em vastos domínios da sociedade, que escapam assim ao controle político imediato, tornou-se uma idéia cada vez mais aceita ao longo do século XIX), econômicas e sociais (industrialização, urbanização), participou plenamente do mesmo movimento, da mesma evolução que transformou a so- 
ciedade e as idéias durante o século XIX. A ciência estatística constituiu parte integrante das ciências sociais e humanas que nasceram durante $\mathrm{O}$ século XIX ${ }^{20}$. Ela os alimentou como, inversamente, as ciências sociais, por sua capacidade de especialização, por seus saberes sobre o social, contribuíram para a elaboração das categorias da estatística e a fabricação de cálculos estatísticos.

Existem muitos índices tangíveis disso: primeiramente, muitos sociólogos participaram de atividades das instâncias estatísticas. É evidentemente o caso de Gabriel Tarde, diretor das estatísticas judiciárias do Ministério da Justiça de 1894 a 1904. Na mesma época (desde 1894) ele era também membro da SPP, verdadeira academia das ciências e dos saberes estatísticos. Ao mesmo tempo, é autor de diversas obras de sociologia e contribuiu para elaborar noções sociológicas como a da imitação. Parece pouco contestável que as estatísticas criminais tenham permitido, senão contribuído para o nascimento da criminologia ou da sociologia criminal $^{21}$. Um pouco mais tarde, o sociólogo durkheimiano François Simiand se tornou membro da SPP (1907), e alcançou sua presidência em 1921. Um de seus companheiros, Maurice Halbwachs, ${ }^{22}$ se tornou também membro da SPP (1921). Eles participaram de fato da atividade de produção es30 tatística na França. Um e outro forneceram muitas obras importantes em sociologia.

Por outro lado, esses autores utilizaram informações estatísticas para elaborar seus conhecimentos sociológicos. O caso mais célebre desse trabalho é evidentemente a análise do Suicídio de Durkheim em 1897. Mas antes dele, pode-se igualmente pensar nos trabalhos de "sociologia empírica " de Quetelet, de Bertillon ou de Le Play ${ }^{23}$.Depois dele, Halbwachs conduziu análises estatísticas finas em muitas de suas principais obras. Sua tese, publicada em 1912 sob o título La classe ouvrière et les niveaux de vie, apóia-se de modo determinante sobre a análise de dados estatísticos alemães (produzidos pela União dos trabalhadores de metais e pelo Office impérial de statistique em 1990). Fundada na observação direta dos fatos, estudos, e no tratamento estatístico desses fatos, sua pesquisa é certamente a primeira tese desse tipo sustentada numa universidade francesa. Seu interesse e sua competência em estatística vieram não apenas de sua inserção na rede durkheimiana, mas também por meio dos cursos de estatísticas ministrados, na época, por Ferdinand Faure na Faculdade de Direito de Paris (ele era antigo presidente da SSP).

Vinte anos mais tarde, Halbwachs realizou um estudo mais amplo sobre o mesmo objeto, L'évolution des besoins dans les classes ouvrières (1933), 
apoiando-se em dados e pesquisas de origens diversas (Bureau international du travail, pesquisas francesas, alemãs, inglesas e americanas). Sua pesquisa sobre as Causes du suicide (1930), que atualiza e corrige a obra de Durkheim sobre o mesmo objeto, repousa igualmente sobre análises de dados estatísticos variados: dados sobre estado civil, processos de médicos e policiais, registros da administração judiciária, anuários ... Enfim, se não fosse necessário reter apenas um exemplo desse diálogo ou desse uso das estatísticas pelos sociólogos, poderíamos pensar em consultar o Année sociologique, revista do grupo ou da rede durkheimiana: ali a estatística (moral) constitui uma rubrica desta revista organizada tematicamente e, segundo as próprias palavras de Durkheim, a estatística é uma ciência auxiliar da sociologia.

Ao participar da objetivação da sociedade, contribuindo com a idéia de que a sociedade não se confunde com o Estado, a estatística é associada à construção da sociologia. $\mathrm{O}$ ato de nascimento da sociologia não é evidentemente único; nem o são os fatores de seu desenvolvimento. Ela incontestavelmente se construiu dialogando ou disputando seu território com a filosofia, a psicologia, a biologia, a história ou o direito ${ }^{24}$. Mas ela nasceu também aproveitando os saberes e dados que a estatística lhe ofereceu. A estatística é um terreno no qual a sociologia vai fixar suas raízes.

Durante os séculos XVIII e XIX, ao se desprender progressivamente de seu sentido antigo que fazia dela um instrumento do Estado, de sua administração e de sua gestão corrente, a estatística tomou uma significação mais moderna: ela se tornou ao mesmo tempo ciência da descrição, isto é, fonte de informação que serve à ciência do registro, de conservação e de análise dos fatos. Hoje, a noção de estatística remete sempre a este sentido. Ela simplesmente se enriqueceu de uma outra significação desde o final do século XIX, sobretudo em ligação com a elaboração de índices e indicadores econômicos: a idéia de informação estatística designa igualmente a idéia de norma, de convenção social, de base comum de acordo, de padrão ${ }^{25}$.

Hoje a idéia de estatística remete à objetividade no sentido clássico ("é objetivo aquilo que é real, aquilo que constitui os fatos, independentemente de nossa percepção") e no sentido social ("objetivo é aquilo que é visto do exterior, que não é subjetivo, isto é, que não depende do ponto de vista de um indivíduo"). Hoje ainda, a atividade estatística, por seus procedimentos taxionômicos, por sua necessidade de identificar formas sociais estáveis, por sua construção de categorias de classificação, participa do conhecimento e da elaboração do social. Nem instrumento de men- 
suração no sentido clássico do termo, nem convenção perfeitamente arbitrária, a estatística é uma das formas de conhecimento do social; mesmo se, como todas as outras formas de saberes sobre o social, ela não pode se libertar de toda interação com o objeto estudado.

Paralelamente a esta história dos dados estatísticos e de seus usos nos trabalhos de conhecimento do social, uma outra história poderia ser contada: a dos utensílios matemáticos de análise desses dados. Em que medida pode-se confiar nos dados calculados pelas amostras? Pode-se generalizar a partir de algumas observações? Pode-se decompor as séries de cifras para fazer surgir as diferentes causas de sua regularidade? ... Essas questões estão entre as muitas que são atribuídas ao nascimento desses instrumentos de cálculos estatísticos e da teoria das probabilidades. Esses instrumentos fazem igualmente parte dos recursos sobre os quais se apoiarão diversas ciências humanas e sociais durante seu desenvolvimento ${ }^{26}$. Mas isso constitui uma outra história, um outro aspecto da mesma realidade histórica.

\section{NOTAS}

${ }^{1}$ Mestre de conferências na Faculté des Sciences Humaines et Sociales de la Sorbonne, Département des Sciences Sociales, Université Paris V; pesquisador do CERLIS ( Centre de Recherche sur les Liens Sociaux, CNRS). E-mail : olivier.martin@paris5.sorbonne.fr. Tradução de Teresa Malatian.

${ }^{2}$ HECHT, Jacqueline. “L'ídée de dénombrement jusqu'à la révolution”. In: Pour une histoire de la statistique. V. 1, INSEE \& Economica, 1987, pp. 21- 81, cit. pp. 23-24.

${ }^{3}$ Colbert, citado em DUPÂQUIER, J e VILQUIN, Eric. "Le pouvoir royal et la statistique démographique”. In: Pour une histoire de la statistique, INSEE \& Economica, 1987, p. 85. Cf. também o precioso livro de GILLE, Bertrand, Les sources statistiques de l'1histoire de France, des enquêtes du XVIIe siècle à 1879. Genève: Droz; Paris: Minard, 1964, pp. 24-27. Esta última obra é uma fonte insubstituível para os historiadores das pesquisas estatísticas na França.

${ }^{4}$ VILQUIN, E. "Vauban, inventeur des recensements". Annales de démographie historique, 1975, pp. 207-219

${ }^{5}$ Jean Bodin, 1576, citado por LE BRAS, Hervé, "La Statistique Générale de la France”. In: NORA, Pierre (dir.). Les lieux de mémoire. V. 1. Paris: Gallimard, 1997, p. 1.356.

${ }^{6}$ BOURGUET, Marie-Noëlle. Déchiffrer la France. La statistique départamentale à l'époque napoléonienne. Paris: Ed. des Archives Contemporaines, 1988, pp. 23-30.

${ }^{7}$ BUCK, Peter. People who counted: Political Arithmetic in the Eighteenth Century.ISIS, v. 73, n. 266, mars 1982, pp. 28-45, especialmente p. 32 e ss.

${ }^{8}$ Para uma abordagem histórica, cf. COUMET, Ernest. La théorie du hasard est-elle née par hasard? Annales ESC, mai-juin 1970, n. 3, pp. 574-598. Para uma abordagem mais filo- 
sófica, cf. HACKING, Ian. The Emergence of Probability: a philosophical study of early ideas about probability, induction and statistical inference. Cambridge University Press, 1975.

${ }^{9}$ Sobre esse contexto e as conseqüências dos trabalhos do marquês de Condorcet, cf. BRIAN, Eric. La mesure de l'État. Administrateurs et gèomètres au XVIII.e siècle. Paris: Albin Michel, "L'évolution de l'humanité", 1994; sobre Condorcet, cf. BAKER, Keith M. Condorcet. Raison et politique. Paris: Hermann, 1989; e sobre a matemática social de Condorcet, cf. GRANGER, Gilles-Gaston. La mathématique sociale du Marquis de Condorcet. Paris: Odile Jacob, 1989.

${ }^{10}$ ROHRBASSER, Jean-Marc. L'arithmétique de la providence. Johan Peter Süszmilch: démographie et psycho-théologie. Thèse de doctorat, EHESS, 1997; ver também a edição parcial de Die Göttliche Ordnung, com o título de "L'ordre divin" aux origines de la démographie. INED e PUF, 1979, 2 v.

${ }^{11}$ HOOCK, Jochen. "D’Aristote à Adam Smith: quelques étapes de la statistique allemande entre le XVII.e siècle et le XIX.e siècle. In: Pour une histoire de la statistique. INSEE \& Economica, 1987, pp. 477-492; DESROSIÈRES, Alain. La politique des grands nombres. Histoire de la raison statistique. Paris: La Découverte, 1993, pp. 29-34.

${ }^{12}$ Seguido pelo Service National des Statistiques (1941-1945), depois pelo INSEE a partir de 1946. Cf. 50 ans d'INSEE ou la Conquête du chiffre, INSSE, 1996, pp. 14-37; DESROSIÉRES, A. Op. cit., pp. 185-200.

${ }^{13}$ MARIETTI, Pascal-Gaston. La statistique générale en France. Paris: PUF, 1949.

${ }^{14}$ BRIAN, Éric. Origines et influences des congrès internationaux de statistique (1853-1876). Comunication à la 47.ème session de l'Institut International de Statistique, Paris, 30 août 1989.

${ }^{15}$ LECUIR, Jean. Criminalité et “moralité”: Montyon, staticien du parlement de Paris. Revue d'Histoire Moderne et Contemporaine, t. 21, juil-sept. 1974, pp. 445-493.

${ }^{16}$ Sobre o lugar do "terreno" na história dos conhecimentos sobre o homem e a sociedade no século XIX, cf. BLANCKAERT, Claude (dir.). Le terrain des sciences humaines: instructions et enquêtes (XVIII.e - XX.e siècle). Paris: L’Harmattan, 1996.

${ }^{17}$ PERROT, Michelle. Premières mesures des faits sociaux: les débuts de la statistique criminelle en France (1780-1830). In : Pour une bistoire de la statistique, cit. p. 125.

${ }^{18}$ DUCHÂTELET, Alexandre Parent. La prostitution à Paris au XIX.e siècle. Texto apresentado e anotado por Alain Corbin. Paris: Seuil, "L’univers historique”, 1981.

${ }^{19}$ LÉCUYER, Bernard-Pierre. Médecins et observateurs sociais: les Annales d'bygiène publique et de médecine légale (1820-1850).In: Pour une histoire de la statistique, cit., pp. 445-476.

${ }^{20}$ SMITH, Roger. The Norton History of Human Science. New-York/Londres: Norton, 1997.

${ }^{21}$ MUCCHIELLI, Laurent (dir.). Histoire de la criminologie française. Paris, L’Harmattan, 1994.

${ }^{22}$ Sobre Halbwachs, ver o número especial que a Revue d'bistoire des sciences humaines, n. 1, 1999, lhe consagrou ( tradução parcial publicada na Revista Brasileira de História, n. 40, v, 21, 2000, n.t.); sobre a concepção das estatísticas em Halbwachs, ver nesse número MARTIN, Olivier. Raison statistique et raison sociologique chez Maurice Halbwachs, pp. 69-101. 
${ }^{23}$ SAVOYE, Antoine. Les débuts de la sociologie empirique. Études socio-historiques (1830-1930). Paris: Méridiens-Klincksieck, 1994; DESROSIÈRES, A. Op. cit., pp. 94-128. CLARK, Terry. Empirical Research in France, 1850-1914. Columbia University Ph.D, 1967.

${ }^{24}$ Os textos de história da sociologia são numerosos. Sobre a sociologia francesa, ver MUCCHIELLI, L. La découverte du social. Naissance de la sociologie en France (1870-1914). Paris: La Découverte, 1998; MARCEL, Jean-Christophe. Le durkheimisme durant l'entre deux-guerres. Paris: PUF, 2000.

${ }^{25}$ MARTIN, Olivier. Regards sur la construction sociale des statistiques. In: La pensée confisquée. Paris: Club Merleau-Ponty/La Découverte, 1997, pp. 173-191; PORTER, Theodore. Trust in Numbers: The Pursuit of Objectivity in Science and Public Life. Princeton, New Jersey: Princeton University Press, 1995.

${ }^{26}$ Sobre a psicologia ver, por exemplo, MARTIN, Olivier. La mesure de l'esprit. Origines et développements de la psychométrie. 1900-1950. Paris: L’Harmattan, 1997. 